\title{
Jujube Phenology, Pollen Germination, and Two Unique Germplasm Resources in New Mexico
}

\author{
Shengrui Yao ${ }^{1}$ \\ Department of Plant and Environmental Sciences, Sustainable Agriculture \\ Science Center at Alcalde, New Mexico State University, Alcalde, NM 87511
}

Additional index words. Ziziphus jujuba, alternative crop, pollen abortion, male-sterile, pseudo-flowers

\begin{abstract}
Jujube (Ziziphus jujuba Mill.) originated in China and grows well in a wide range of areas in the United States, especially the southwest. New Mexico State University's Sustainable Agriculture Science Center has imported and collected over 50 jujube cultivars and conducted a series of jujube-related research projects. In this study, jujube phenology and pollen germination in New Mexico were investigated and two unique germplasm resources were reported. Jujubes leafed out 4-8 weeks later than most pome and stone fruits and bloomed 2-3 months later than apricots, peaches, and apples. It can avoid late frosts in most years in northern New Mexico and, thus, produce a crop more reliably than traditional fruit crops in the region. For the 48 cultivars tested for pollen germination, the germination rates ranged from $0 \%$ to $75 \%$ depending on the cultivar and year. 'September Late' had the highest pollen germination rate each year among all cultivars tested from 2012 to 2014, whereas 'GA866', 'Maya', and 'Sherwood' had the lowest. 'Zaocuiwang' was the first reported male-sterile jujube cultivar in the United States, and this character was consistent from year to year and, thus, it would be a valuable cultivar for jujube breeding. Cultivar Yu had pseudo-flowers which never bloomed or set fruit. It would be a useful germplasm as special landscape trees or for genomic study of jujube flowering-related genes.
\end{abstract}

Jujube, also called Chinese date, originated in China and has been cultivated there for 4000 years (Guo and Shan, 2010). There are over 800 cultivars in China (Liu and Wang, 2009), whereas in the United States, less than 10 cultivars are commercially available (Yao, 2013). Both commercial jujube growers and home gardeners in the United States demand a wider choice of cultivars to expand the maturation season and for different end uses.

Jujubes grow and produce well in a wide range of areas in the United States, especially in the semiarid southwest (Yao, 2013). But, commercial growers and home gardeners are affected by poor fruit set in some cases because of non-self-fruiting cultivars and lack of pollinizers.

To meet the cultivar demands in the United States, we have built a collection of over 50 cultivars: some collected in the United States and the majority directly imported from

\footnotetext{
Received for publication 19 Sept. 2017. Accepted for publication 8 Nov. 2017.

This project was funded by a specialty crop block grant through the New Mexico Department of Agriculture and the New Mexico Agricultural Experiment Station, and Hatch funds from the USDA National Institute of Food and Agriculture. We thank Steve Guldan, Richard Heerema, and Marisa Thompson from New Mexico State University for reviewing this manuscript. We also thank Junxin Huang, Robert Heyduck, David Salazar, and David Archuleta for their technical assistance.

${ }^{1}$ Corresponding author. E-mail: yaos@nmsu.edu.
}

China (Yao, 2013). We have been evaluating them since acquisition. For cultivars, selffertile, partial self-fertile, and self-sterile all exist and cross-pollination always increases fruit set and fruit size over self-pollination (Yao et al., 2015). Cultivars for different purposes and pollinizer recommendations are needed. There are several studies regarding pollen amount and pollen germination from China (Guo and Shan, 2010; Han et al., 2008; Liu and Peng, 1992), but no such studies in the United States.

Phenology provides basic information about a fruit species introduction and is helpful for planting region expansion, especially marginal regions. Adding phenological data and pollen germination information to our knowledge of cultivars would greatly assist cultivar recommendation for particular growing areas in North America. We have reported jujube cultivar flowering and fruiting habits, cultivar vitamin $\mathrm{C}$ profile, and sugar composition dynamics in the past (Huang et al., 2017; Yao et al., 2015). The objectives of this study were to observe jujube phenology and pollen germination of different jujube cultivars collected in New Mexico. The two unique germplasm resources of 'Zaocuiwang' and 'Yu' were identified during the phenology observation and pollen study process.

\section{Materials and Methods}

This experiment was conducted at New Mexico State University's Sustainable Agriculture
Science Center, Alcalde, NM (lat. $36^{\circ} 05^{\prime} 28^{\prime \prime} \mathrm{N}$, long. $106^{\circ} 03^{\prime} 25^{\prime \prime} \mathrm{W}$, and $1737 \mathrm{~m}$ elevation). There are over 50 jujube cultivars at the NMSU Alcalde Center (Yao et al., 2015). As trees were planted or grafted in different years, not all cultivars were used for every test in this study. Among those cultivars, Abbeville, Lang, Li, Sihong, Shuimen, Shanxi Li, Globe, Redland, Don Polenski, Fitzgerald, and So were planted in 2006, whereas Jin, Sui, and Topeka were planted in 2011. Also in 2011, 30 cultivars were imported from China as scion wood and grafted to wild jujube rootstocks (Z. spinosa) that had been planted in 2010 (Yao et al., 2015). Depending on precipitation, trees were irrigated once per week with drip irrigation or flood irrigation during growing season, and around $56 \mathrm{~kg} \cdot \mathrm{ha}^{-1}$ nitrogen, $28 \mathrm{~kg} \cdot \mathrm{ha}^{-1}$ phosphorus and $56 \mathrm{~kg} \cdot \mathrm{ha}^{-1}$ potassium were applied in split applications before bloom.

Phenology was observed for all cultivars listed in Yao et al. (2015) plus 'Yu' twice per week from mid-April to full bloom, through fruit set and around fruit maturation time each year from 2012 to 2017 . Last frosts were also recorded each spring. For budding/leafing, jujube's phenology is different from that of pome and stone fruits. We used $2 \mathrm{~mm}$ green as the budding stage standard (Fig. 1).

The pollen germination studies were conducted around the full bloom or late full bloom period from late June to early July from 2012 to 2014. Cultivars tested in each year are listed in Table 1. The morning bloom types were sampled between 0700 and $0800 \mathrm{HR}$ and the afternoon blooming types were sampled between 1200 and 1300 HR (Yao et al., 2015). Twelve to fifteen same-day bloomed flowers were sampled and stored in Eppendorf tubes and transported to the laboratory in ice. Cultural media were prepared with $15 \%$ sucrose, $0.01 \%$ boric acid, and $1 \%$ agar, and $\mathrm{pH}$ was adjusted to 5.8 (Han et al., 2008).

For pollen germination tests, $0.35-0.4 \mathrm{~mL}$ of media was used per slide and smeared with a glass rod. With jujube's small flowers, direct inoculation was used in this study (Han et al., 2008). Each cultivar had three slides as replications with four to five flowers on each slide. Each slide was put into a petri dish with a piece of wet paper towel to buffer the humidity. Petri dishes were stored in a covered tub. After $4-5 \mathrm{~h}$ of incubation at

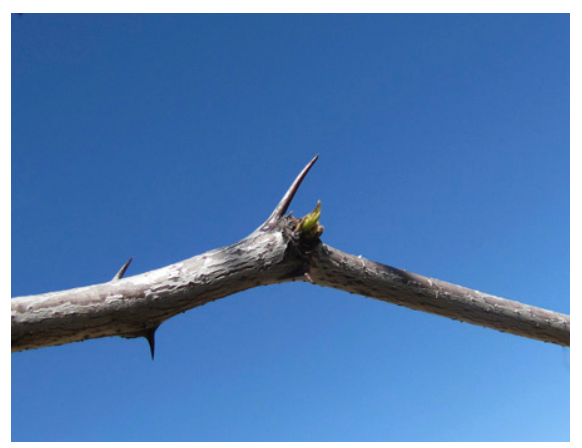

Fig. 1. Jujube in the budding stage with $2 \mathrm{~mm}$ green. 
Table 1. Jujube cultivar pollen germination rates from 2012 to 2014 at Alcalde, NM. The last nine cultivars had only 1 year of observation, for reference only.

\begin{tabular}{|c|c|c|c|c|}
\hline Cultivar & 2012 & 2013 & 2014 & Mean $\pm \mathrm{SE}$ \\
\hline September Late & 84.2 & 64.9 & 73.8 & $74.3 \pm 6.8$ \\
\hline Shuimen & 48.7 & - & 67.9 & $58.3 \pm 13.6$ \\
\hline Zhongning & - & 57.7 & 58.6 & $58.1 \pm 0.6$ \\
\hline QYX & 50 & 45.7 & 63 & $52.9 \pm 6.4$ \\
\hline Chaoyang & 53.1 & - & 67.9 & $52.8 \pm 10.8$ \\
\hline Sihong & 49.7 & - & 63.9 & $51.9 \pm 7.8$ \\
\hline Daguazao & 46.1 & 41.5 & 42.4 & $43.3 \pm 1.7$ \\
\hline Jinsi-4 & 35.1 & 37.2 & 53.9 & $42.1 \pm 7.3$ \\
\hline Fitzgerald & 51 & 32 & 37.9 & $40.3 \pm 6.9$ \\
\hline Honeyjar & 46.4 & - & 39.7 & $39.7 \pm 9.4$ \\
\hline Dabailing & 36.6 & - & 38.7 & $37.7 \pm 1.5$ \\
\hline Dragon & 29.8 & 16.2 & 66.5 & $37.5 \pm 18.4$ \\
\hline Lang & 31.7 & 26.9 & 52.4 & $37.0 \pm 9.6$ \\
\hline Yuanling & 47.8 & 23.9 & 38.5 & $36.7 \pm 8.5$ \\
\hline Jin & 37.5 & - & 35.5 & $36.5 \pm 1.4$ \\
\hline $\mathrm{Li}$ & 38.7 & 37.1 & 28.1 & $34.6 \pm 4.1$ \\
\hline $\mathrm{Li}-2$ & 37.8 & 26.7 & 35.8 & $33.4 \pm 4.2$ \\
\hline Jun & 32.6 & 30.9 & 33.8 & $32.4 \pm 1.0$ \\
\hline Don Polenski & 34 & 23.5 & 36.4 & $31.3 \pm 4.8$ \\
\hline Xiang & - & 36.5 & 40.2 & $30.6 \pm 9.6$ \\
\hline $\mathrm{KFC}$ & 23.6 & - & 35.8 & $29.7 \pm 8.7$ \\
\hline Jinsi-2 & 21.7 & 14.7 & 34 & $23.5 \pm 6.9$ \\
\hline Shanxi Li & - & 24.9 & 21.4 & $23.2 \pm 1.8$ \\
\hline Xingguang & 18 & 20.8 & 27.9 & $22.2 \pm 3.6$ \\
\hline Jixin & 19.9 & 15.7 & 26.8 & $20.8 \pm 4.0$ \\
\hline Jinchang & 16.7 & 25.5 & 12.6 & $18.3 \pm 4.7$ \\
\hline Pitless & 15.7 & 9.1 & 20.5 & $15.1 \pm 4.0$ \\
\hline Jinsi-3 & 19.6 & 16.1 & 8.6 & $14.8 \pm 4.0$ \\
\hline Miyunxiaozao & 20.1 & 12 & 7 & $13.0 \pm 4.7$ \\
\hline Globe & 6 & 8.9 & 21.3 & $12.1 \pm 5.7$ \\
\hline Abbeville & 4.1 & 21.8 & 9.2 & $11.7 \pm 6.5$ \\
\hline Sugarcane & 4.6 & 22.4 & 7.8 & $11.6 \pm 6.7$ \\
\hline Sherwood & - & 8.5 & 11.7 & $10.1 \pm 2.3$ \\
\hline Jing-39 & 6 & 14.1 & - & $10.1 \pm 4.1$ \\
\hline Maya & 7.9 & 8.9 & 8.1 & $8.3 \pm 0.4$ \\
\hline JKW & - & 6.9 & 4 & $5.5 \pm 2.1$ \\
\hline $\mathrm{ZFC}$ & 3.3 & 7.8 & 3.2 & $4.8 \pm 2.6$ \\
\hline GA866 & - & 1.7 & 4.2 & $3.0 \pm 1.7$ \\
\hline $\mathrm{ZCW}$ & 0 & 0 & 0 & \\
\hline Ant admiral & & & 36.4 & 36.4 \\
\hline Youzao & & & 34.6 & 34.6 \\
\hline Mushroom & & & 29.3 & 29.3 \\
\hline $\mathrm{Mu}$ & & & 28 & 28 \\
\hline Thornless & & & 23.7 & 23.7 \\
\hline Redland & & & 21 & 21 \\
\hline LYX & & & 11.5 & 11.5 \\
\hline Gaga & & & 10.4 & 10.4 \\
\hline Topeka & & & 8.3 & 8.3 \\
\hline
\end{tabular}

$22{ }^{\circ} \mathrm{C}$, pollen germination was observed and photographed under a microscope. Around 200 pollens were counted for pollen germination rate and abortion rate.

For cultivar Zaocuiwang, its phenology and pollen germination were observed as were those of others. When we noticed the male-sterile character of 'Zaocuiwang' in 2012, observations with dissecting scope and microscope were conducted in the following years to compare its anther structure and pollen grains with those of 'Lang'. For cultivar $\mathrm{Yu}$, we observed its phenology together with other cultivars since 2012. A more detailed observation was conducted for its flower development and inflorescence structure in 2016 and 2017. Pictures were taken both in the field and under a dissecting scope.

For the pollen germination data, the germination rate for each cultivar per year was the average of three slides. As we did not budding order varied slightly from year to year. The budding time also varied with location, climate, cultivar, age, and tree condition. Late frosts affected the phenology in 2014 and 2015. In 2015, some cultivars started to bud out around 10 Apr., but the frost on 18 Apr. killed the early growth and reset the budding process of those early cultivars. In 2014 , the $-4.4{ }^{\circ} \mathrm{C}$ on 15 May killed the early growth of all cultivars and interrupted the normal development of branchlets and new shoots, but the jujube trees regenerated themselves and leafed out again 2-3 weeks later. With temperature warming up in June, the blooming process was delayed slightly, but fruit matured normally in 2014. In 2017, there were light frosts in late May, but it only affected some young leaves. The budding time ranged from midApril to mid-May at Alcalde, NM, depending on cultivars and climate conditions.

As branchlets budded out, leaves flattened out and flower buds started to form in leaf axils. Primary buds bloomed first, then secondary, followed by tertiary. The first bloom was from mid-June to late June and full bloom was in late June to early July each year at Alcalde, NM. In comparison, apricots, peaches, cherries, and apples bloomed from mid-March to mid-April each year and varied slightly from year to year at Alcalde, NM.

Jujube cultivars bloomed from June to August depending on the climate, tree condition, and cultivar. Jujube fruit matured from mid-September to early October each year at Alcalde, NM. Because of the killing frost around 10 Oct. each year, late cultivars could not fully mature in most years at Alcalde, NM.

Pollen germination. Average values across the years revealed that pollen germination rates of 48 jujube cultivars varied from $0 \%$ to $75 \%$ (Table 1). 'Zaocuiwang' was the only one without pollen, whereas 'September Late' had the highest pollen germination rate each year among all cultivars tested. Cultivars September Late, Chaoyang, Shuimen, Zhongning, Sihong, and QYX had average pollen germination rates of $50 \%$ or higher, whereas the pollen germination rates of cultivars Sherwood, Jing-39, Maya, JKW, ZFC, GA866, Gaga, and Topeka were $10 \%$ or lower (Table 1).

The high germination cultivars had welldeveloped pollen grains, whereas the low germination cultivars had a high percentage of aborted pollen grains (Fig. 2).

A male-sterile cultivar - Zaocuiwang. Jujube cultivar Zaocuiwang had no pollen in the anthers but aborted pollen sacs, and this character was consistent from 2012 to 2017 , whereas the anthers of 'Lang' were loaded with pollen grains (Fig. 3).

'Yu' with pseudo-flowers. 'Yu' was purchased from a California family nursery. The tree growth and leaves were similar to those of other jujube cultivars with possible branched branchlets (Fig. 4). We observed the phenology of 'Yu' from 2012 to 2017 and never noticed any bloom or fruit on ' $\mathrm{Yu}$ '. 'Yu' did have flower clusters, but each flower 

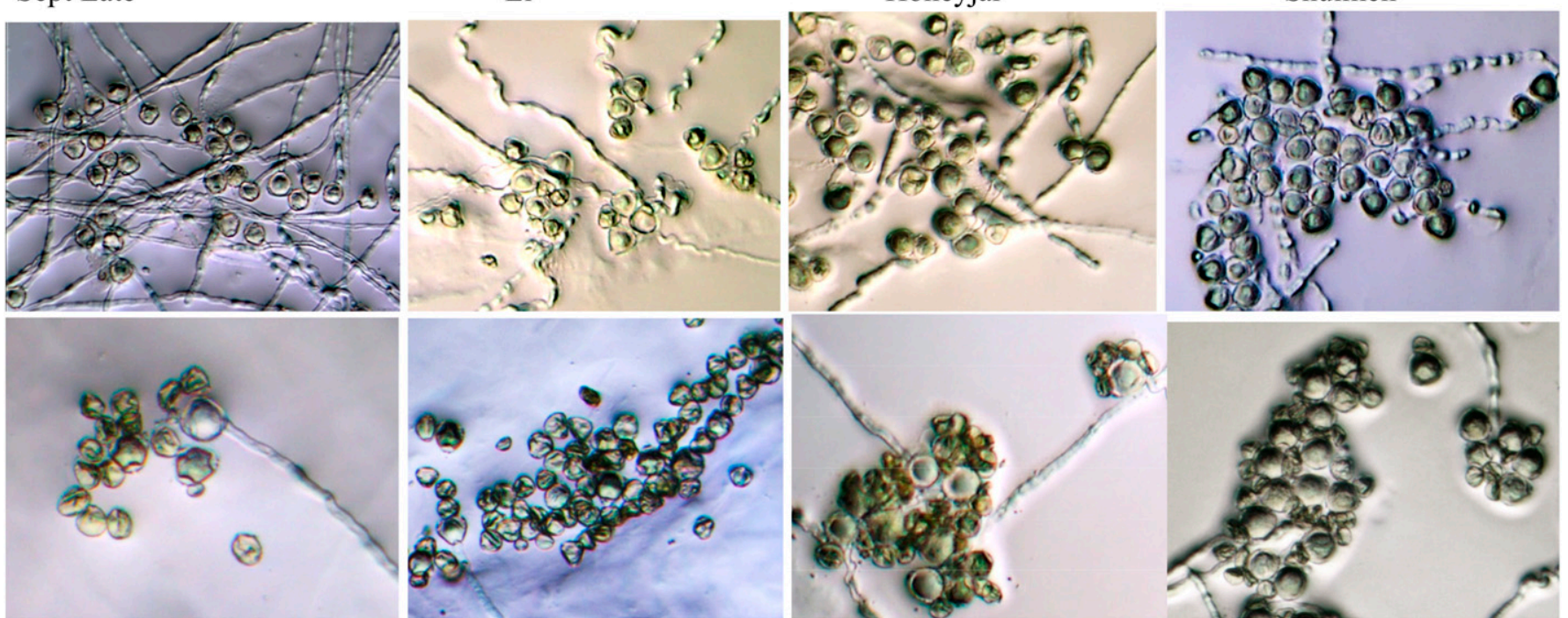

'GA866'

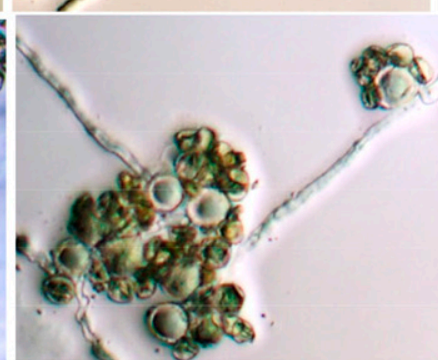

'Topeka'

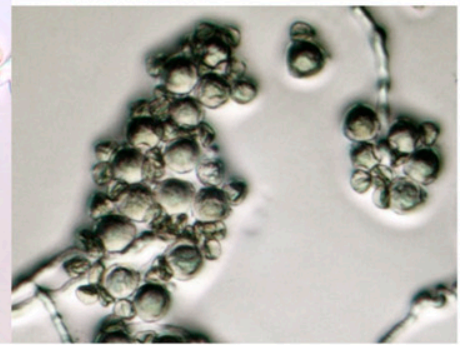

'Sugarcane'

Fig. 2. Pollen germination of different jujube cultivars in 2014 at Alcalde, NM.
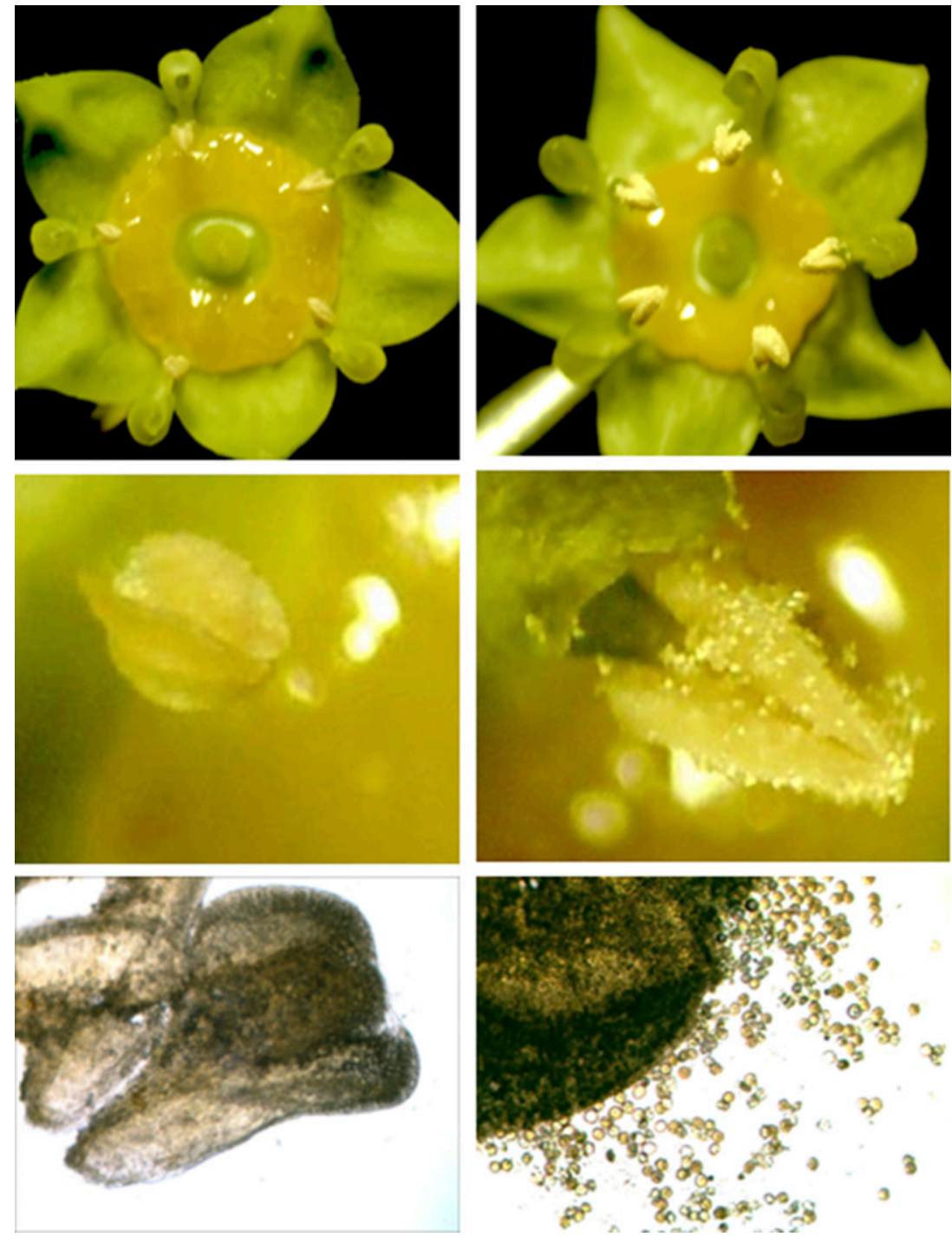

Fig. 3. Flowers (top), anthers, and pollen grains (middle and bottom) of jujube cultivars: Zaocuiwang (left) and Lang (right) in 2014 at Alcalde, NM. 'Zaocuiwang' had small shrunken anthers without pollen grains. bud was much smaller than flower buds of other cultivars, with flower bud diameter less than $1.5 \mathrm{~mm}$ (Figs. 4 and 5). Flowers of 'Yu' never opened up or bloomed, but turned yellow and fell off, with no male or female parts observed. All three 'Yu' plants did not set any fruit between 2013 and 2017 at Alcalde. 'Yu' has a more complicated fruit inflorescence than other common jujube cultivars (Fig. 5). Common jujube flower clusters were classified as dichasium with one primary flower (Fig. 6) in the middle, whereas for the flower cluster of 'Yu', it was not a single primary flower but a flower cluster in the middle. They normally had three clusters of flowers in each inflorescence, occasionally four clusters. The extremely short pedicels made it difficult to examine clearly the inflorescence structure. They were all determinate inflorescences and the middle cluster could be the dominant one, with structure similar to a compound cyme but more complicated (Fig. 6). The flower number ranged from several to 15 flowers depending on the node in a branchlet and branchlet position, and it could be over 40 little flowers in one inflorescence on a woody branchlet (data not shown). The flower cluster was not symmetric, and tertiary and quaternary flowers could have been aborted because of nutrient competition and location of the cluster on the branchlet.

\section{Discussion}

Jujube is a good alternative crop for late frost-prone areas. Jujubes leaf out in midApril to mid-May at Alcalde, NM. Apricots bloom in early to mid-March, late March to early April for peaches, and early to midApril for apples at Alcalde, NM. Jujubes bear flowers in leaf axils as an inflorescence (Yao, 2013; Yao et al., 2015). Jujubes begin blooming 
in June and continue for $2-2.5$ months within a single tree with its flower inflorescences and branches of different ages in northern New Mexico.

With its late start-up, nutritious fruit (Huang, et al., 2017; Zhao et al., 2017), and good drought tolerance (Hager and Edward, 1989), jujube is a good alternative and reliable crop in many areas, especially in late frost-prone areas (Yao, 2012). First, it leafs out 4-8 weeks later than most tree fruit species and avoids most late frosts by blooming in June through early August. Second, if drought or late frost does occur, jujubes keep blooming and setting fruit, compensating for early losses, if any. Even if the early growth were frost-killed in mid-May as occurred in 2015, they still can regenerate themselves, set fruit, and mature (Yao and Zhao, 2016).

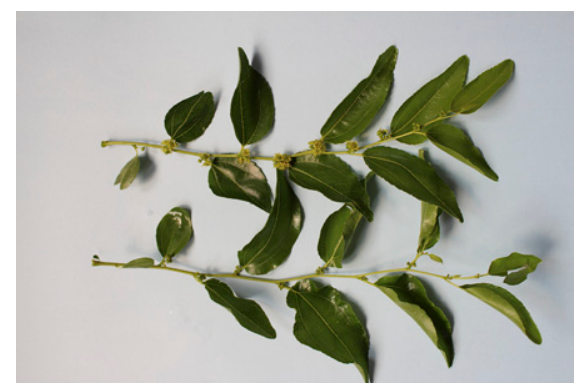

Fig. 4. Branchlets of 'KFC' (upper) and 'Yu' (lower) on 27 June 2017.
Third, jujube is a drought-tolerant plant, and its shorter growing season also helps to save more water than other pome and stone fruit crops with a greater water demand and a longer season. The standard pome and stone fruits are not reliable in northern New Mexico (Yao, 2012), but jujube has produced a crop every year since we started the jujube research in 2010 compared with two to three crops for apples and peaches from 2010 to 2017. Jujube's reliable crops were also reported in early studies (Hager and Edward, 1989; Locke, 1948; Lyrene, 1979; Meyer, 1916; Thomas, 1927). Jujubes do have suckers and it can become problematic if trees are abandoned, especially in hot and humid areas. In New Mexico, we noticed more suckers in the Las Cruces area than in the northern part of the state.

Although jujubes can avoid or recover from most late frosts with their late leafing, they are not frost tolerant. In areas with short growing seasons, growers should select the early and midseason cultivars and avoid later maturing ones because the early killing frost will end the season and defoliate the branchlets, leaves, and fruits.

Pollen quality, germination, and pollinizer selection. Compared with pure pollen inoculation, direct inoculation is not the best method to study pollen germination, but it can screen a high volume of cultivars in a relatively short period of time. Liu and Peng (1992) reported that the ideal media would be $0.5 \%$ to $1 \%$ agar,
$10 \%$ to $20 \%$ sucrose, and $0.01 \%$ boric acid at $30{ }^{\circ} \mathrm{C}$ with $70 \%$ to $100 \%$ relative humidity. Liu and Peng (1992) did not mention the media $\mathrm{pH}$ range. Han et al. (2008) used similar media with $1 \%$ agar, $15 \%$ sucrose, and $0.01 \%$ boric acid, and $\mathrm{pH}$ at $5.5-6.2$ at $28{ }^{\circ} \mathrm{C}$. The pollen germination rates of $0 \%$ to $75 \%$ in this study were similar to those of Han et al. (2008) and Guo and Shan (2010), but higher than those of Liu and Peng (1992) and Li et al. (2006). Differences in cultivars used and culture conditions all can contribute to differences in pollen germination rates. 'September Late' is an imported Chinese cultivar which had the highest pollen germination rate in this study, similar to the previous report by Guo and Shan (2010).

Jujube has self-fruitful cultivars, but cross-pollination is recommended for all cultivars for better fruit set and bigger fruit size (Guo and Shan, 2010; Yao et al., 2015). The high and medium pollen germination groups are good for pollination purposes. Cultivars with a high percentage of aborted pollen grains and low pollen germination rate cultivars are not recommended as pollinizers. Cultivars with high-quality pollen and good germination are recommended as pollinizers for this latter group of cultivars. Although the primary concerns of jujube growers may be fruit yield and quality, pollen quality and germination rate should also be considered in cultivar/pollinizer selections.

Male-sterile germplasm in jujube breeding. 'Zaocuiwang' is the first reported male-sterile
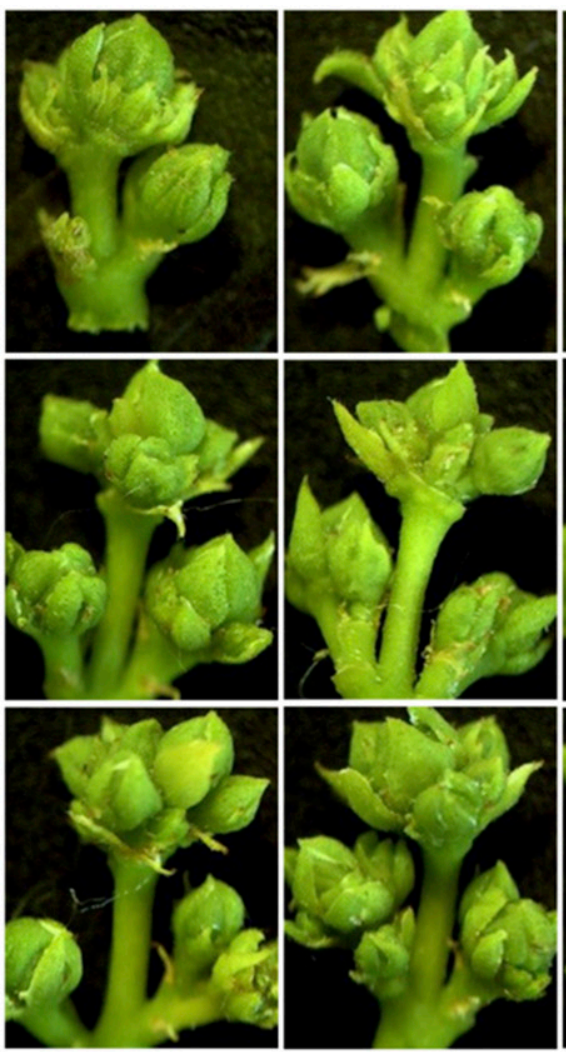
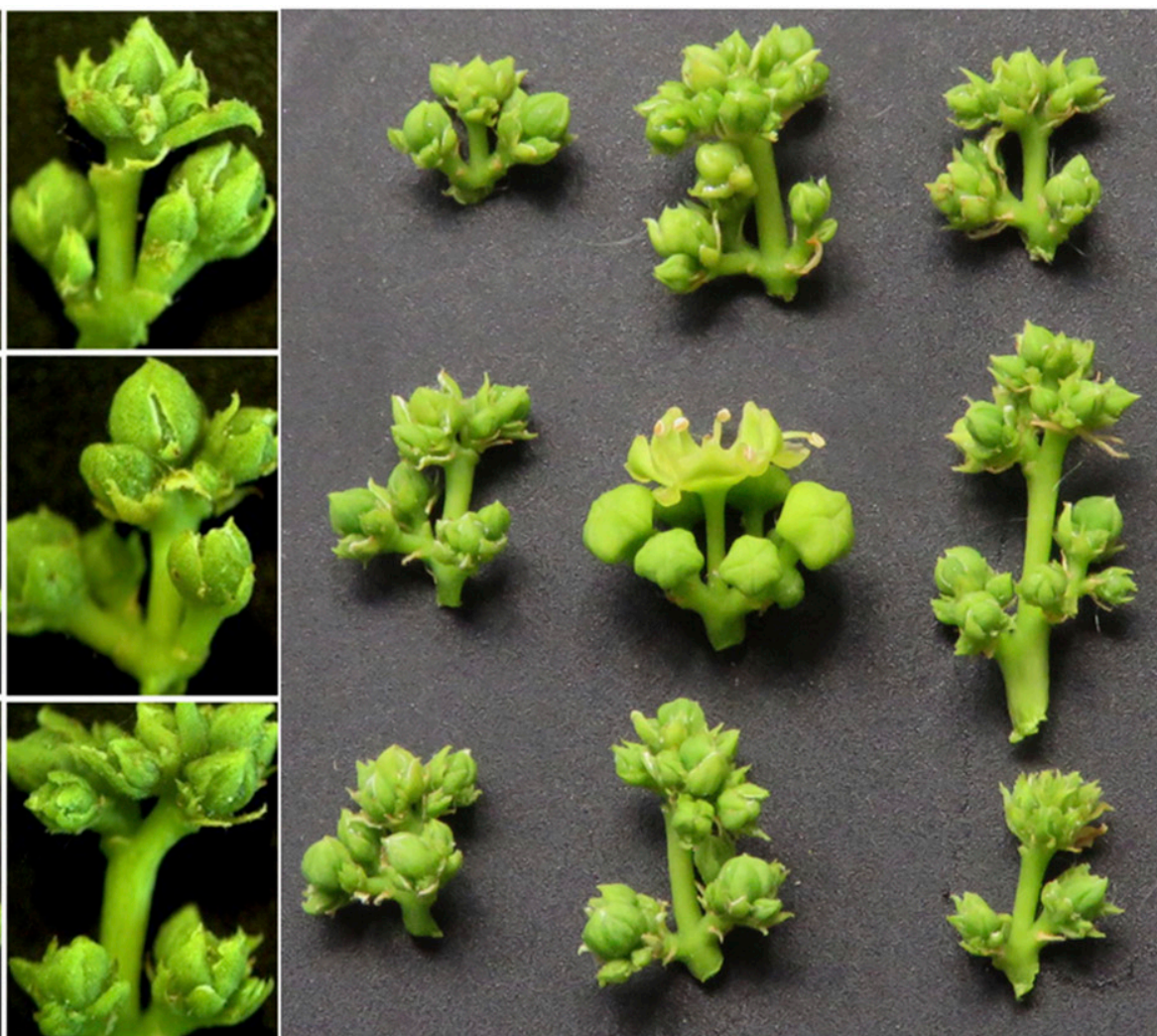

Fig. 5. Flower clusters of 'Yu' (nine on the left, taken on 22 June 2017) and their comparison with a normal jujube flower cluster in the middle (right, taken on 27 June 2017). The middle flower on the right side is 'KFC', which was a younger cluster near the tip of the branchlet, specially picked to demonstrate the flower cluster structure. The main flower clusters from nodes 2-6 were in full bloom with 3-5 flowers clustered together which block the view of the inflorescence structure, whereas no flower was blooming for 'Yu' on 27 June 2017. 

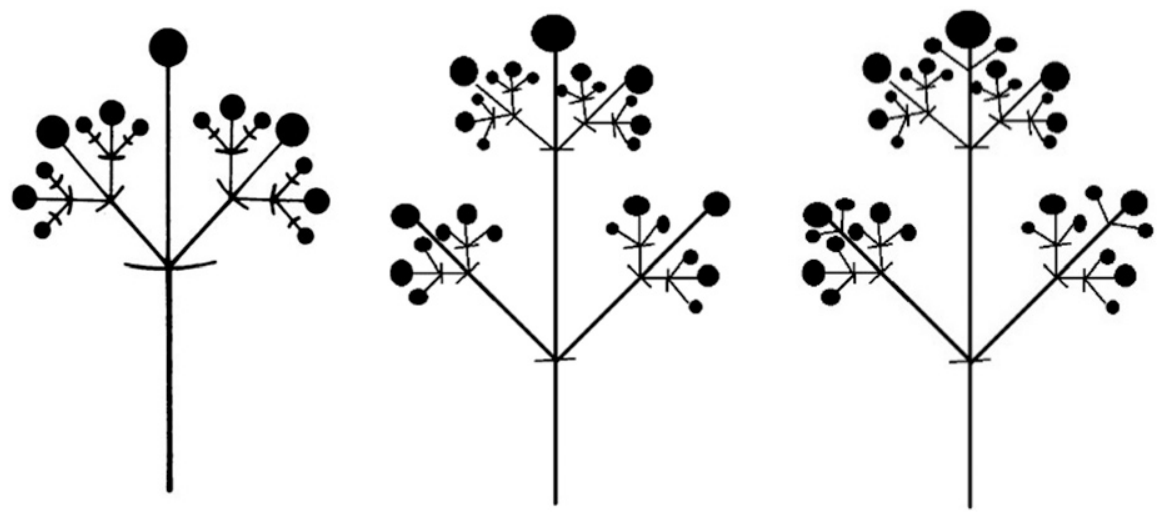

Fig. 6. Dichasium (normal jujube inflorescence, left), compound cyme (middle), and the inflorescence of 'Yu' (right).

jujube cultivar in the United States. It may be the same as JMS1 in China (Wang et al., 2006). 'Zaocuiwang' was not mentioned as male-sterile in its cultivar introduction in China (Sun et al., 2001). As we started to write this manuscript, it was reported that cultivar Zaocuiwang was male-sterile in China (Li et al., 2017). Fruit shape of 'Zaocuiwang' was similar to that of 'Shandong Li' (Guo and Shan, 2010) in China and it could be a strain or a mutation from 'Shandong Li'. 'Shandong Li' itself is a male-sterile cultivar as previously reported (Guo and Shan, 2010). Wang et al. (2006) reported that the pollen of JMS1 was aborted after the tetrad stage.

Jujubes have small flowers with a diameter of 6-7 mm (Liu, 2006; Yao et al., 2015), which makes emasculation almost impossible. Even if emasculation could be done manually, it would still be difficult to have enough hybrid seeds with jujube's low fruit set-one to several percent (Guo and Shan, 2010; Yao et al., 2015). Also, jujube flowers are borne in an inflorescence in each leaf axil, so there are always flowers emerging after the emasculation which can complicate any attempts at hybridization. So far, the $800+$ jujube cultivars in China and worldwide are all from open pollination/selections-none is a manipulated hybrid yet (Guo and Shan, 2010; Liu and Wang, 2009).

Cultivar Zaocuiwang has large fruit and is early or midseason in maturation with seeds (Li et al., 2017; Yao et al., 2015). It would be a perfect female parent for jujube breeding without emasculation.

Germplasm with pseudo-flowers. Roger Meyer claimed that ' $Y u$ ' was the original cultivar imported by Frank Meyer in 1913
(Meyer, 1991; Yao, 2013). Frank Meyer described it as possessing a tooth-shaped fruit with excellent quality. There was no searchable information about 'Yu' after that. Roger Meyer never mentioned anything about its fruit characteristics. It could be a mislabeled scion wood importation by Frank Meyer or something else that was mistaken in the 1990s as Frank Meyer's original 'Yu', or it was a mutation of the original 'Yu' of Frank Meyer.

'Yu' has flower clusters with smaller flower buds than regular jujube cultivars. We did not notice any bloom or fruit in the past 6 years. These kinds of pseudo-flowers are not common in jujube cultivars (Z. jujuba Mill.). When home gardeners or fruit growers choose jujubes for fruit production, 'Yu' should not be on their list.

In general, jujubes are good edible landscape trees with shiny leaves and sweet fruit. The so-called 'Yu' would be a good germplasm when people just need a landscape tree with nice shade, shiny leaves, and ease of care, with no pollen grains and no fruit when people want to avoid allergy from pollen and no mess from falling fruit. ' $\mathrm{Yu}$ ' is also a valuable germplasm for jujube genomic research of jujube flowering-related genes.

\section{Literature Cited}

Guo, Y. and G. Shan. 2010. The Chinese jujube. Shanghai Scientific and Technical Publishers, Shanghai, China (in Chinese).

Hager, M.D. and T. Edward. 1989. My favorite tree, the jujube. Calif. Rare Fruit Grow. Nwsl. 21(2):31-32.

Han, B., J. Li, Z. Xu, and J. Peng. 2008. Studies of blooming biology and pollen sprouting characteristics of different Chinese jujube cultivars. Chinese Agr. Sci. Bul. 24:167-170 (in Chinese).
Huang, J., R. Heyduck, R.D. Richins, D. VanLeeuwen, M.A. O'Connell, and S. Yao. 2017. Jujube cultivar vitamin $\mathrm{C}$ profile and nutrient dynamics during maturation. HortScience 52:859-867.

Li, B., H. Li, and T. Wei. 2017. Jujube cultivar Zaocuiwang, male-sterile identification and verification. Jiansu Agr. Sci. 45(4):91-92. (in Chinese)

Li, L., J. Wang, M. Liu, and J. Zhou. 2006. Pollen number and germination rate of different Chinese jujube cultivars. J. Plant Genet. Resources 7:338 341. (in Chinese).

Liu, M. 2006. Chinese jujube: Botany and horticulture. Hort. Rev. 32:229-298.

Liu, M. and J. Peng. 1992. Studies of pollen storage and germination in Chinese jujube wild jujube. J. Beijing Agr. College 7:172-177. (in Chinese).

Liu, M. and M. Wang. 2009. Germplasm resources of Chinese jujube. China Forestry Publishing House, Beijing, China (in Chinese).

Locke, L.F. 1948. The Chinese jujube: A promising fruit tree for the southwest, p. 78-81. In: Oklahoma crops and soils, 1947: Research reported at the Second Annual Oklahoma Crops and Soils Conference. Oklahoma Agr. Expt. Sta. Bul. B319.

Lyrene, P.M. 1979. The jujube tree. Fruit Var. J. 33:100-104.

Meyer, F.N. 1916. China a fruitful field for plant exploration, p. 205-224. In: USDA yearbook of agriculture 1915. U.S. Dept. Agr., Washington, DC. 5 July 2017. <http://naldc.nal.usda.gov/ download/IND43843025/PDF>.

Meyer, R. 1991. The jujube and the plan introduction station at Chico, California. Pomona 24(1):31-35.

Sun, Z., J. Wang, and D. Kong. 2001. A new fresh eating early jujube cultivar-Zaocuiwang. Hebei Fruits 2001(3):48-49 (in Chinese).

Thomas, C.C. 1927. Chinese jujube in southwestern United States, p. 212-215. In: USDA yearbook of agriculture 1926. U.S. Dept. Agr., Washington, DC. 6 July 2017 . <http://naldc.nal.usda.gov/ download/IND43842740/PDF>.

Wang, J., L. Liu, M. Liu, and J. Zhou. 2006. Acquirement of new male sterile germplasm of Chinese jujube. Acta Hort. Sin. 33:374-377 (in Chinese).

Yao, S. 2012. Jujube, chinese date in New Mexico. New Mexico State Univ. Coop. Ext. Publ. H-330.

Yao, S. 2013. Past, present, and future of jujubesChinese dates in the United States. HortScience 48:672-680.

Yao, S., J. Huang, and R. Heyduck. 2015. Jujube (Ziziphus jujuba Mill.) flowering and fruiting in the southwestern United States. HortScience 50:836-849.

Yao, S. and Z. Zhao. 2016. Jujube in the United States: Challenges and opportunities. Acta Hort. 1116:23-29.

Zhao, Z., R. Richins, M. O'Connell, and S. Yao. 2017. Cyclic adenosine monophosphate (cAMP) in fruit and leaves of jujube cultivars grown in New Mexico. ASHS Annual Conference, Waikoloa, HI, 19-22 Sept. 2017. 